\title{
COMPARATIVE EFFECT OF RADIOACTIVE RADIATION ON ROOTS IN COASTAL AND HINTERLAND LOCATIONS IN AKWA IBOM STATE, NIGERIA.
}

\author{
Godfrey T. Akpabio and Eno E. Ituen \\ Department of Physics, University of Uyo, Uyo, Nigeria
}

(Submitted: 27 May, 2005; Accepted: 14 February, 2006)

\begin{abstract}
The detection of the radiation levels in root crops from Ibeno (an oil producing area) and Uyo, (a non oil producing area) in Akwa Ibom state was carried out. The radioactivity level in Cassava, Potato, Sweet yam, water yam and cocoyam was investigated. Result shows that the radiation level in root samples in Uyo ranges between $8.58 \mathrm{mBqg}$ and $1.06 \mathrm{mBqg}^{-1}$ as compared with those from Ibeno, which ranges between $34.7 \mathrm{mBqg}^{-1}$ and $3.7 \mathrm{mBqg}^{-1}$. Yam and cassava samples from Ibeno have the highest radioactive levels of $34.7 \mathrm{mBqg}^{-1}$ while water yam sample in Uyo has the highest radioactive level of radioactive materials in roots than Uyo. This is probably due to the oil producing activities in the area.
\end{abstract}

Keywords: NORM, radioactivity, ionization, roots.

\section{Introduction}

Akwa ibom state is an oil producing state in Nigeria. As a result of the production of oil and oil spillage, naturally occurring radioactive material (NORM), has been distributed into the Environment.

The nature of the root system of a plant and the depth to which it extend vertically and laterally depend upon factors as the soil moisture, the soil air and temperature and the physical nature of the soil. Roots play several roles in the life of the plant they anchor the plant in the soil, they absorb water and minerals from the soil, they transport these minerals from the region of absorption to the base lof the stem and they may serve as food accumulating organs (Wilson et al, 1971).

Three types of radiations have been identified alpha particles, beta particles and gamma rays. In any radioactive disinfiguration, the alpha or beta particles will be emitted, it may be accompanied by a gamma ray.

The rate at which radioactive materials disintegrate or decay is amost independent of all physical and chemical conditions. The activity of a radioactive sample can be expressed in terms of its rate of decay, that is the number of disintegration per second in the sample (Holwill and silvester, 1976).

There are a number of devices that can be used to detect the particle and photons emitted when a radioactive nucleus decays. Such devices detect the ionization that these particles and photon cause as they pass through matter (Cutnell and Johnson, 1998). In traving techniques, with the presence of a radioactive substance is easily detected with a Geiger Muller counter, based on the ionization produced by the radioactive emanations, (Eno, 1998). A Geiger Muller tube is widely used for detecting ionizing particles or radiation (Nelkon and Parker, 1977).

\section{Material and Methods}

Cassava, potato, sweet yam, water yam and cocoyam roots were obtained each from two locations in Akwa Ibom State, that is, Ibeno and Uyo. The roots gotten from Ibeno were from Mkpanek and Upenkang in Ibeno Local Government Area. The ones gotten from Uyo were from Udoette Street in Uyo Local Government Area.

Geiger-Muller counter was used for this experiment to detect the radiation emitted by these roots. Each root sample was merged before taking readings.

Geiger-Muller tube was used for this experiment with a dekatron counter. The tube was callibrated as expected to obtain its characterization curve.

Each sample was washed thoroughly with deionized water and then cut into piece the peel, bottom, middle and head close to the stock. A 
particular piece was weighed and marshed one after another and poured into a $30 \mathrm{ml}$ breaker to obtain its counting rate. Thus four values of counting rate were obtained for each root sample. After every measurement the beaker was washed and ringed again.

The average of the four values is used for required analysis. Thus the value of each root sample given in the tables is actually the average of four values taken with four pieces cut out of the sample.

\section{Result and discussion}

The result for the radiation levels in each of the root samples for the two locations are presented in Tables 1 and 2.

Table 1 which is the experimental results for Ibeno roots shows that yam and cassava have the highest radiation count of $34.7 \mathrm{mBq} \cdot \mathrm{g}^{-1}$ and water yam the least of $3.48 \mathrm{mBq} \cdot \mathrm{g}^{-1}$. Table 2 for Uyo roots shows that water yam has the highest radiation count of $8.55 \mathrm{mBq} \cdot \mathrm{g}^{-1}$ and sweet yam the least of $1.06 \mathrm{mBq} \cdot \mathrm{g}^{-1}$.

A histogram Fig. 1 gives us the comparative analysis display for the two locations showing yam and cassava with the highest radioactive levels whereas water yam appear to have highest in Uyo. We can deduce that the source of radioactivity is mainly due to the environment and not just the rootGenerally figure 1 shows that roots in Ibeno have a higher radioactive level as compared to roots from Uyo, a non oil producing area many (oil) drilling sites and production facilities have radioactive materials associated with them. Some of these radioactive materials, primarily tracers of logging tools are deliberately brought to the site for use while other materials are naturally occurring and are called naturally occurring radioactive materials (NORM). during drilling water based drilling muds and cuttings are discharged overboard (FAQ), Drilling fluids used for onshore wells are primarily disposed of in reserves pit. While in many areas drilling fluids from offshore

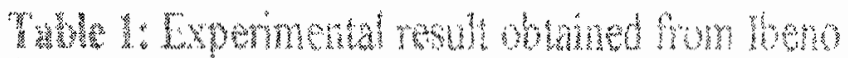

\begin{tabular}{|c|c|c|c|c|c|c|}
\hline Sample & 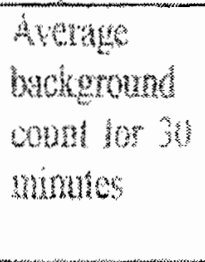 & 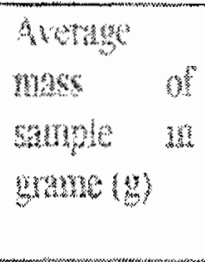 & 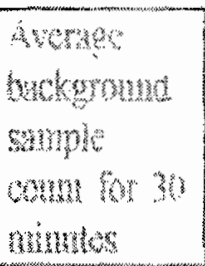 & 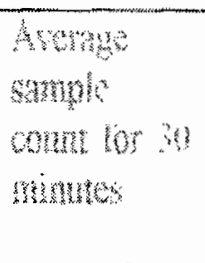 & 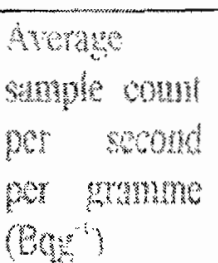 & 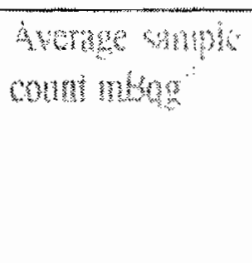 \\
\hline Cossent? & 3211 & 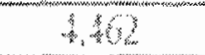 & 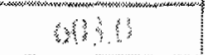 & 210 & $(169)^{20}$ & 73 \\
\hline mato & 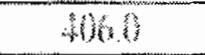 & 4.114 & 583 & 38 & 61172 & 192 \\
\hline Swotswn & 91113 & $3 \mathrm{kn}$ & 3 (6) & hin & 91101 & $1 ?$ \\
\hline Yan & 3515 & 1.28 & 680 & $3 n !$ & $\sqrt{\operatorname{mon}^{2}}$ & 817 \\
\hline Water yum & 3603 & 6.646 & 3196 & 41,3 & Whon & 348 \\
\hline Coconsm & 277 & 7 sys: & $2 \pi, 8$ & 9,1 & N1Wh & 6.96 \\
\hline
\end{tabular}

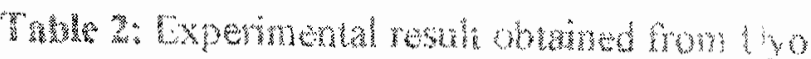

\begin{tabular}{|c|c|c|c|c|c|c|}
\hline Sunvple & 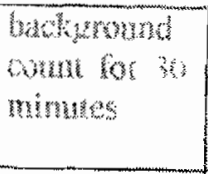 & 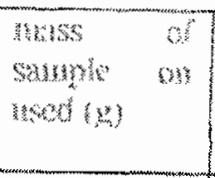 & 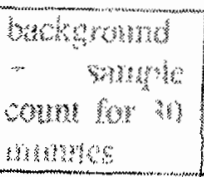 & 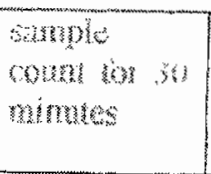 & 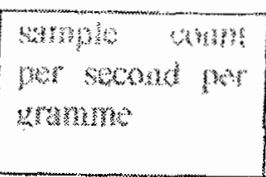 & 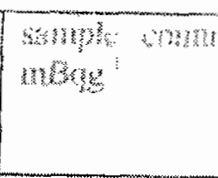 \\
\hline Constery & 35.10 & 3625 & 121. & 63,40 & $(068)$ & 3.11 \\
\hline matas & 3226 & 6.813 & 381.13 & 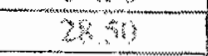 & 0131 & 3.3 \\
\hline Syeos yam & 801.6 & $52 \pi{ }^{3}$ & 311 & पिएक & $7+13100$ & 130 \\
\hline Yaxu & 3583 & 13868 & 364 & 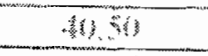 & 6,6513 & 514 \\
\hline Woter wasts & .748 .75 & 37.58 & 3043 & 885 & nombs8 & $28 x$ \\
\hline Conotstn & 31868 & 545 & 35 & $+21 n$ & 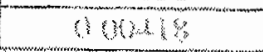 & $1 \%$ \\
\hline
\end{tabular}


platforms have been dumped overboard. (Reis, 1996). When oil is species on water, it spreads out over the water surface and moves with the wind and water currents (Reis, 1996). This water gets into the swamps and has effect on the crops planted in these areas. This should be the case with Ibeno. Since the level of permissible radioactivity level is $360 \mathrm{mBq} \cdot \mathrm{g}^{-1}$, these levels of radioactive material in roots are not harmful ti

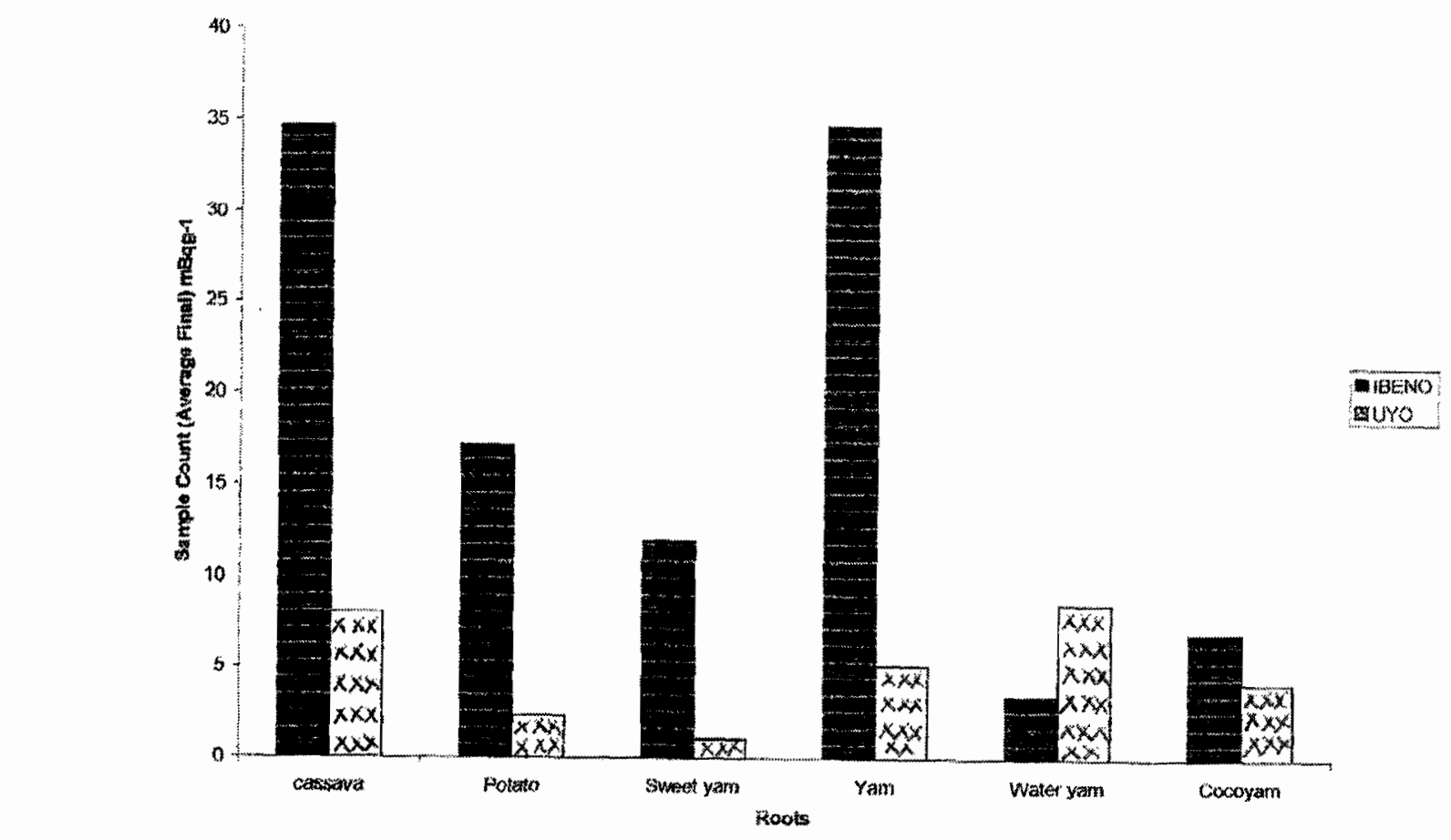

is not harmful today, continous accumulation may make it significant and harmful tomorrow.

\section{Conclusion}

The result of the study shows that Ibeno has a higher level of radioactive materials in roots than in Uyo. This is probablv due to the oil activities in the area..

Fig. 1: A histogram for the comparison of the radiation levels in roots from two locations in Akwa Ibom State; viz Ibeno (an oil prosducing area) ands Uyo (an non-oil producing area)

Generally, Fig. 1 shows that roots in Ibeno have a higher radioactive level as compared to roots from Uyo, a non oil producing area many (oil) drilling sites and production facilities have radioactive materials associated with them. Some of these radioactive materials, primarily tracers of logging tools are deliberately brought to the site for use while other materials are naturally occurring and are called naturally occurring radioactive materials (NORM). during drilling water based drilling muds and cuttings are discharged overboard (FAQ), Drilling fluids used for onshore wells are primarily disposed of in reserves pit. While in many areas drilling fluids from offshore platforms have been dumped overboard. (Reis, 1996). When oil is species on water, it spreads out over the water surface and moves with the wind and water currents (Reis, 1996). This water gets into the swamps and has effect on the crops planted in these areas. This should be the case with Ibeno. Since the level of permissible radioactivity level is $360 \mathrm{mBq} \cdot \mathrm{g}^{-1}$, these levels of radioactive material in roots are not harmful to human health. Even though the current level is not harmful today, continous accumulation may make it significant and harmful tomorrow.

\section{Conclusion}

The result of the study shows that Ibeno has a higher level of radioactive materials in roots than in Uyo. This is probably due to the oil activities in the area.

\section{Acknowledgements}

Iwish to acknowledge the contribution of Imabong U. Obo in the data acquisition. 


\section{References}

Cutnell, T. D. and Johnson, K. W. (1998): Physics, John Wiley and Sons. Inc $4^{\text {th }}$ Edition. P. 976-973

Eno, E. E. (1998): Electricity and Modern Physics. Footsteps Publications. Port Harcourt P. 204 -211.

FAO Offshor Discharges from oil and Gas Development Operations http://www.gomr.mms.gov/homepg/of fshore/egom/factshee.html.

Holwill, M. E. and Silvester, N. R (1976): Introduction to Biological Physics. John Wiley and Sons. London. P. 323325.
Mgbenu, A. E.; Inyang, A. E.; Agu, M. N; Osuwa, J. C. and Ebong I. D. U. (1995): Modern Physics, Nigerian University Physics Series, Spectrum Books Limited.

Nelkon, M. and Parker, P. 91977): Advanced level Physics $4^{\text {th }}$ Edition. Heinemann, Educational Books Ltd. London, 946 954.

Reis, J. C. (1996): Environmental Control in Petroleum Engineering. Gulf Publishing Company. Houston P. 261264.

Wilson, C. L.; Looms, W. E. and Steeves, T. A. (1971): Botany, Hott, Rinehart and Winston, Inc . 